\title{
TRANSABDOMINAL ULTRASONOGRAPHIC EVALUATION OF FETAL WELL-BEING IN THE LATE-TERM MARE AND COW
}

\author{
Boglárka BASKA-VINCZE ${ }^{*}$, Ferenc BASKA ${ }^{2}$ and Ottó SZENCI $^{3}$ \\ ${ }^{1}$ Equine Department and Clinic, Faculty of Veterinary Science, Szent István University, \\ Dóra major, H-2225 Üllö, Hungary; ${ }^{2}$ Department of Pathology, Faculty of Veterinary \\ Science, Szent István University, Budapest, Hungary; ${ }^{3}$ Hungarian Academy of Sciences, \\ Large Animal Clinical Research Group, Üllö, Hungary
}

(Received 24 February 2014; accepted 25 June 2014)

\begin{abstract}
In the equine practice, attempts have been made to examine the fetus in the second and third trimester of pregnancy but all of the available methods have limitations. Until now, transabdominal ultrasonography has been regarded as the most informative examination. This method allows us to measure fetal heart rate, fetal activity as well as the quality and quantity of the fetal fluids. A modified biophysical profile for horses was used by several researchers in the USA from the 1990s as a gold standard. However, it is not sensitive enough and, in the authors' experience, professionals can face difficulties during its application (e.g. for measuring aortic diameter and fetal breathing movements). In cows, this method was first used for this purpose by a Canadian research group in 2007. They reported that transabdominal ultrasound was promising but showed low sensitivity in this species. The present studies show that birth weight cannot be predicted from fetal aortic diameter measurement in cows as suggested by other researchers. Transabdominal ultrasound needs special equipment (2-3.5 MHz convex transducer) and basic ultrasonographic knowledge; however, we suggest that in most cases it can be performed with the dam placed in a stock and without shaving the examination area. The method provides useful information within 30-40 minutes, enabling the examiner to determine whether or not the fetus is alive and to recognise placentitis or twins. This technique also allows measuring the combined thickness of the uteroplacental unit, and the authors' ongoing study showed higher normal values in Lipizzaner mares compared to values in other breeds. In conclusion, with the help of advanced techniques, simple and low-cost methods should be developed for the evaluation of the pregnant dam and its fetus to assess fetal viability in the veterinary practice.
\end{abstract}

Key words: Fetal well-being, equine, bovine, ultrasonography, high-risk pregnancy

In human obstetrics, transabdominal ultrasonography has been used for 30 years to evaluate the well-being of the fetus. Various methods have been de-

\footnotetext{
*Corresponding author; E-mail: Vincze.Boglarka@aotk.szie.hu; Phone: 0036 (20) 259-4909; Fax: 0036 (29) 521-303
} 
scribed for assessing the fetus by ultrasonography in normal and high-risk pregnancies in order to recognise fetal distress and compromise. Manning was a pioneer of this field, and developed a fetal biophysical profile (BPP) to evaluate the vitality of the human fetus in utero (Manning et al., 1980). This profile consists of the sonographic evaluation of the following five variables: fetal breathing movements, generalised fetal movements, fetal tone, amniotic fluid index (AFI), and transient accelerations in response to fetal movements (reactive heart rate). Each criterion is given a score of 0 to 2 and the sum of all scores gives the overall result. Scores of 8 to 10 are considered normal. The usefulness and applicability of this method were studied in many institutions in the last 30 years. It has been described that the BPP score strongly correlates with perinatal mortality and morbidity, and thus the BPP is an effective tool used all over the world for the antepartum assessment of fetal well-being in late-term high-risk pregnancies (Manning et al., 1980, 1984, 1985, 1986, 1987; Manning, 1990).

For at least 40 years, equine researchers and practitioners have been searching for a reliable method to assess fetal well-being; therefore, transabdominal ultrasonography (also called transcutaneous ultrasonography) has been used to evaluate late-term equine fetuses since the 1980s (Palmer, 2000). The first antepartum evaluations on equine fetuses were performed in the 1980s, when a BPP for horses and the technique and application of transabdominal ultrasonography in mares were described (Pipers and Adams-Brendemuehl, 1984; Adams-Brendemuehl and Pipers, 1987). Then a modified equine BPP from 298 days gestational age to term was developed. This profile 'specific to the equine fetus' includes six factors related to pregnancy outcome: fetal heart rate, fetal aortic diameter, maximal fetal fluid depths, uteroplacental contact, uteroplacental thickness and fetal activity. This profile provided information about fetal wellbeing, perinatal morbidity and perinatal mortality in the mare. As in the case of Manning's biophysical profile for the human fetus, each variable was given a score of 0 if it was abnormal and a score of 2 if it was normal. Then the scores were summed up. A low score was a definite indication of an impending negative outcome; however, a high score did not provide assurance that the delivery would have a positive outcome (Reef et al., 1995, 1996; Reef, 1998). This BPP became the 'gold standard' for transabdominal ultrasonography for many years in the examination and treatment of pregnant mares in the clinical practice.

LeBlanc (1996) published a review on antepartum fetal assessment in horses. She reported that a variety of techniques were used for clinical evaluation of the equine fetus, including palpation per rectum, collection of blood for hormone analysis, collection of mammary secretions for the determination of electrolyte concentrations, fetal electrocardiography, fetal ultrasonography and amniocentesis, but each technique had some limitations. Simple blood samples were not informative in the hormone measurements, while rectal palpation was not sensitive enough because only a small part of the fetus could be reached by hand. 
Monitoring fetal heart rate (FHR) with an electrocardiogram was not informative in itself without additional information because of the variability in heart rate and rhythm during equine and human pregnancy (Vaala and Sertich, 1994). Under clinical and stud conditions, non-invasive techniques are preferred or required by the owners (LeBlanc, 1996).

Renaudin et al. (1997) suggested that the transrectal sonographic assessment of mid- and late-term pregnant mares should be added to the BPP because of its diagnostic value in evaluating fetal fluids and the uteroplacental unit. By transrectal sonography, the combined thickness of the uteroplacental unit near the cervical star can be measured. This is important because an ascending placentitis can be easily recognised by this imaging modality (Palmer, 2000).

Reimer (1997) examined a large number of high-risk pregnant mares ( $\mathrm{n}=$ 122) by transcutaneous ultrasonography in a retrospective manner. Nearly $40 \%$ of the 122 high-risk pregnancies showed abnormality by sonography and $32 \%$ of them were associated with a negative outcome. The authors concluded that this examination was valuable in the diagnosis, management and prognosis of highrisk equine pregnancies (Reimer, 1997).

However, Palmer (2000) reported that the predictive value of a normal biophysical test was not as high in horses as in human beings, and clinical experience indicates that the predictive value of an abnormal test falls short of the ideal. The equine BPP has a mix of parameters resulting from acute or chronic hypoxia. It was also described that fetal monitoring techniques of universal applicability should be developed. The lack of sensitivity and specificity of the BPP may be caused by the selection of the parameters measured. The equine BPP shows promise but still requires refinement (Palmer, 2000).

Still, most authors have found that transabdominal ultrasonographic evaluation of the equine fetus in normal and high-risk pregnancies is critically important in perinatology (Pantaleon et al., 2003; Troedsson, 2007; Whitcomb, 2008; Ousey and Fowden, 2012). Useful data were collected from late-term pregnant mares ( $\mathrm{n}=$ 150) with normal pregnancies by Bucca et al. (2005), who also made a validation study to compare the ultrasound measurements to actual organ sizes $(\mathrm{n}=6)$. A positive correlation was found between the ultrasonographic and the actual measurements, but both the differences and the correlations were significant $(\mathrm{P}<0.05)$. In 3 out of 6 cases the difference between sonographic and postmortem measurements was more than $13 \mathrm{~mm}$. Therefore, it was concluded that more data were needed before performing ultrasonographic validation (Bucca et al., 2005).

In a more recent study, clinicians have shown that a relatively new development of human medicine is also available for veterinary use. With the modern 3D ultrasound imaging it is possible to visualise congenital and clinical disorders such as fetal deformities in the mare (Kotoyori et al., 2012).

In cattle, transrectal examinations became an everyday practice in the field already some time ago, but the method of transabdominal ultrasonographic ex- 
aminations has only recently been described by Buczinski et al. (2007). The authors discussed current knowledge and future perspectives in fetal well-being assessment (Buczinski et al., 2007) and highlighted the significance of transabdominal ultrasonography in cloning technology because of the high incidence of developmental anomalies in cloned calves (Buczinski et al., 2009).

A detailed work was published about the technical requirements and protocol of transabdominal ultrasonographic assessment in late-term pregnant cows (Buczinski, 2009). Then, measurements and attempts to create a BPP for the bovine fetus were made, and normal $(\mathrm{n}=10)$, high-risk $(\mathrm{n}=10)$ and cloned $(\mathrm{n}=$ 10) late-term pregnant cows were examined by Buczinski et al. (2009). They showed that the components of Reef's BPP are not as informative in the prediction of pregnancy outcome in cattle as in horses. On the one hand, they could observe long resting periods during the 10-min examinations when the calves did not make any movement, so fetal activity was graded as zero without any negative consequences. In horses, fetal activity strongly correlates with fetal wellbeing (Reef et al., 1995, 1996; Reef, 1998). In the equine fetus, thoracic aortic diameter is a sensitive predictor of birth weight but in cattle the correlation coefficient is not so high (Buczinski et al., 2011). This parameter needs further investigation because intrauterine growth retardation (IUGR) and large fetuses frequently occur in Holstein-Friesian cows, and it would be an advantage for the practitioners working on dairy farms to know whether or not the fetus has normal size. In case of a too large fetus, early intervention could be performed. According to the authors' ongoing study $(\mathrm{n}=42)$, fetal aortic diameter in HolsteinFriesian cows and heifers does not correlate with the birth weight. As described by Buczinski et al. (2007), 42 Holstein-Friesian cows and heifers were examined by transabdominal ultrasonography 10 days before parturition and the fetal aortic diameters were measured. The correlation between this parameter and the birth weight was evaluated. Unfortunately, no correlation could be established (BaskaVincze et al., unpublished). Buczinski's research group has concluded that, just like in horses, transabdominal ultrasonography is a useful technique for evaluating the fetus and the uterine environment in cows, but more detailed studies are needed to diagnose fetal abnormalities more accurately and to improve the management of high-risk pregnancies in cattle (Buczinski, 2009; Buczinski et al., 2007, 2009, 2011).

\section{Examination procedure}

\section{Patient preparation}

In cows, sometimes it is possible to restrain the dam only by holding her head (Buczinski, 2009), but according to other authors and in the authors' experience, for safety reasons horses and cows should be placed in a stock wherever they are examined (Reef et al., 1995, 1996; Reef, 1998; Baska-Vincze et al., 2013, 2014). 
For the examination of horses it is recommended to clip the hair surgically over the ventral abdomen. The size of the clipped area depends on the gestational age (Pipers and Adams-Brendemuehl, 1984; Reef, 1998; Bucca et al., 2005). In late-term mares, this area usually extends from the mammary gland to the xiphoid process and includes both sides of the abdomen (Fig. 1). Although the use of surgical clipping has been recommended, in the authors' experience this is not necessary. Horses with a fine hair coat can be scanned properly without clipping. However, it is very important to remove any dirt possibly present on the skin surface as this can decrease the contact between the ultrasound transducer and the skin (Baska-Vincze et al., 2013, 2014).

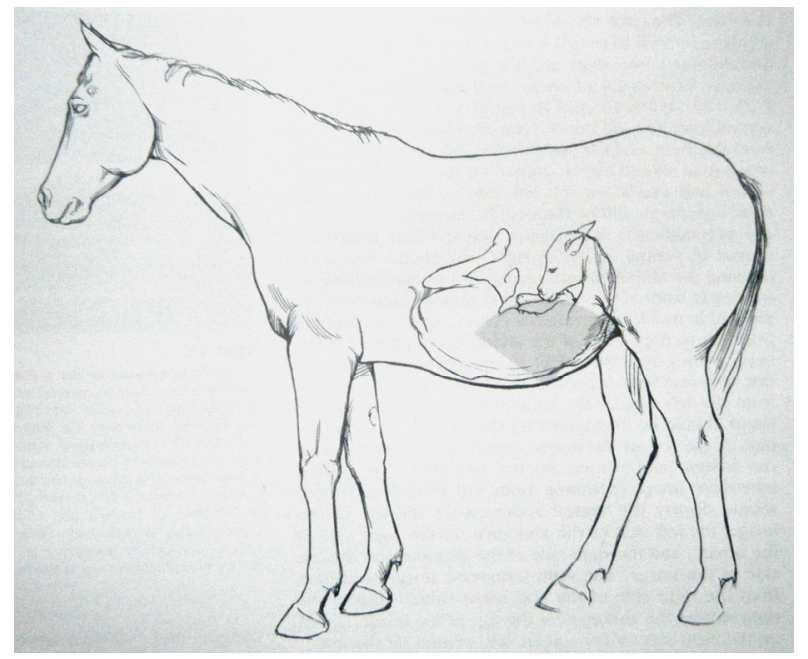

Fig. 1. Position and presentation of the foal fetus in the mare in late gestation (adapted from V. B. Reef: Equine Diagnostic Ultrasound, Saunders, Philadelphia, 1998)

Because of the anatomical conformation, in cows the ventral part of the right abdomen must be shaved in caudocranial direction from the udder to the end of the milk vein cranially. This area extends to the horizontal line $15 \mathrm{~cm}$ dorsal to the stifle on the right and to the linea alba on the left (Buczinski, 2009). In the authors' experience, both shaving and clipping can often be avoided in cows. In heifers, the fetus may sometimes move in cranial direction close to the xiphoid or sometimes caudally to the base of the udder. In these cases thorough scanning is required (Baska-Vincze et al., unpublished).

\section{Technique and ultrasonographic findings}

The method of transabdominal ultrasonographic evaluation in the mare was described in detail previously (Reef et al., 1995; Reef, 1998). Since this first description, the protocol has not been modified significantly. 
In mares and cows, transabdominal ultrasonography of the fetus can be performed with a $2.5-3.5 \mathrm{MHz}$ macro- or microconvex transducer capable of reaching 20-30 $\mathrm{cm}$ penetration depth. However, the uteroplacental unit can be scanned better by the use of higher frequencies, usually between $6-10 \mathrm{MHz}$ with a penetration of 4-10 $\mathrm{cm}$. At present, different ultrasound transducers are available for clinicians and veterinarians working under field conditions. In both species, diluted ethanol or propanol and ultrasound gel can be used on the skin surface to increase penetration depth and image quality (Reef, 1998; Baska-Vincze et al., 2013, 2014).

During the examination of a pregnant mare, the scanning starts in front of the mammary gland and moves cranially. The first task is to locate the fetal thorax with the typical sight of the fetal ribs (Fig. 2). In the cow, the examination is similar but it should be done on the right side as described by Buczinski (2009). If the fetal thorax is found (Fig. 3), the fetal aorta should be located and the aortic diameter measured. The callipers of the ultrasound should be placed to the leading edge of the aortic walls as close to the heart as possible (Reef, 1998). It has been reported that fetal aortic diameter correlates with neonatal birth weight and maternal weight in both the mare $(\mathrm{n}=30)$ and the cow $(\mathrm{n}=13)$, and equations have been developed to estimate body weight (Reef et al., 1995, 1996; Buczinski, 2009).

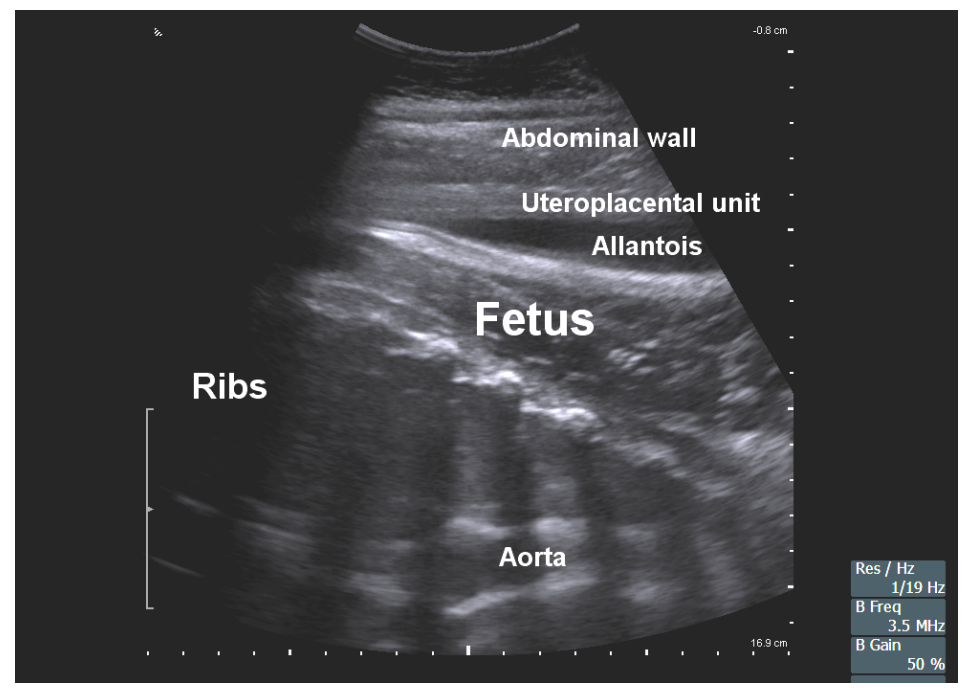

Fig. 2. The equine fetal thorax (imaged with a 3.5-MHz macroconvex ultrasound probe in lateromedial direction in a 285 days pregnant warmblood mare)

The uterus of the mare should be thoroughly scanned to ascertain that only one fetus is present. If twin pregnancy is detected, special attention must be paid to decreasing its negative consequences. Twins can be present in $7-10 \%$ of dairy cow 
pregnancies and, although they are considered abnormal, they have less complication than in horses (Szelényi et al., 2011). After locating the fetal thorax, the presentation of the fetus can be defined. In late gestation, the head of the fetus is normally positioned towards the pelvis. If it is found in the abdomen, dystocia can occur, so both the mare and its fetus should be closely monitored (Reef, 1998).

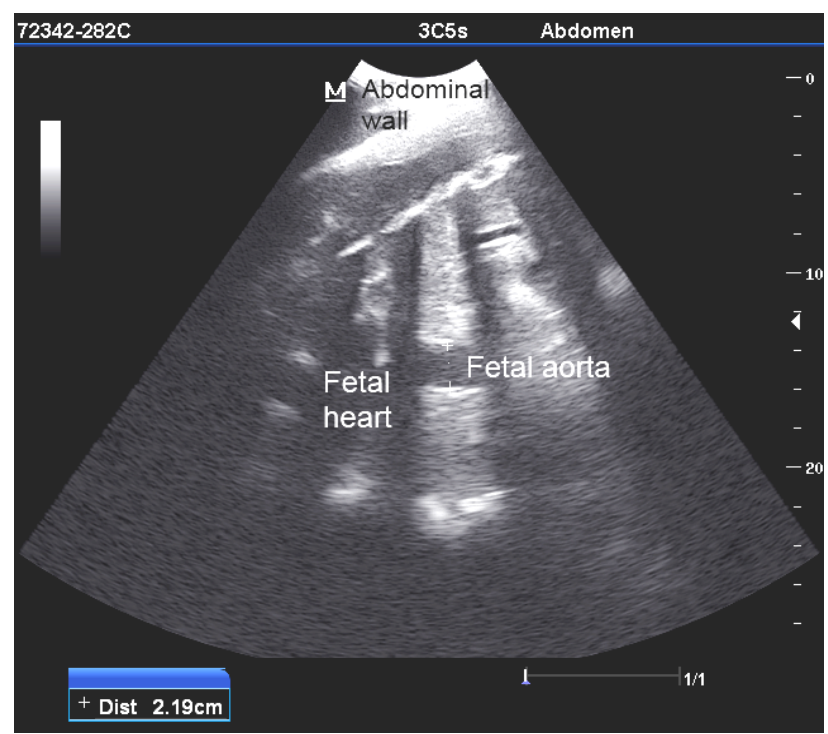

Fig. 3. The bovine fetal thorax (imaged with a 3.5-MHz macroconvex ultrasound probe in right lateromedial direction in a 270 days pregnant Holstein-Friesian cow)

Ultrasonographic identification of cardiac activity and determination of fetal heart rate have been shown to be useful indicators of fetal health in both the mare and the cow. Most of the ultrasound scanners make it possible to measure fetal heart rate using M-mode or B-mode. When using M-mode, the fetal heart should be positioned to the sonographic marker and the heartbeat waves are visualised on the screen. Then, after freezing the image, the distance between the peaks can be marked, and the machine counts the heart rate which is displayed directly on the screen (Fig. 4). The other possibility to measure the heart rate is to count the number of beats during a 15-, 30- or 60-sec interval as viewed on the B-mode ultrasound screen (Curran and Ginther, 1995).

Attempts have been made to measure and examine the FHR in cattle by cardiotocography and ultrasonography. Normocardia (heart rates of 80 to 155 beats per minute) and tachycardia (heart rates of $>155$ beats per minute) were detected by cardiotocographic recording in 84 fetuses during the dilatation stage of parturition, and a close correlation was found between the heart rate and the degree of acidosis. All fetuses having tachycardia showed acidosis or severe acidosis (Held et al., 1986). 


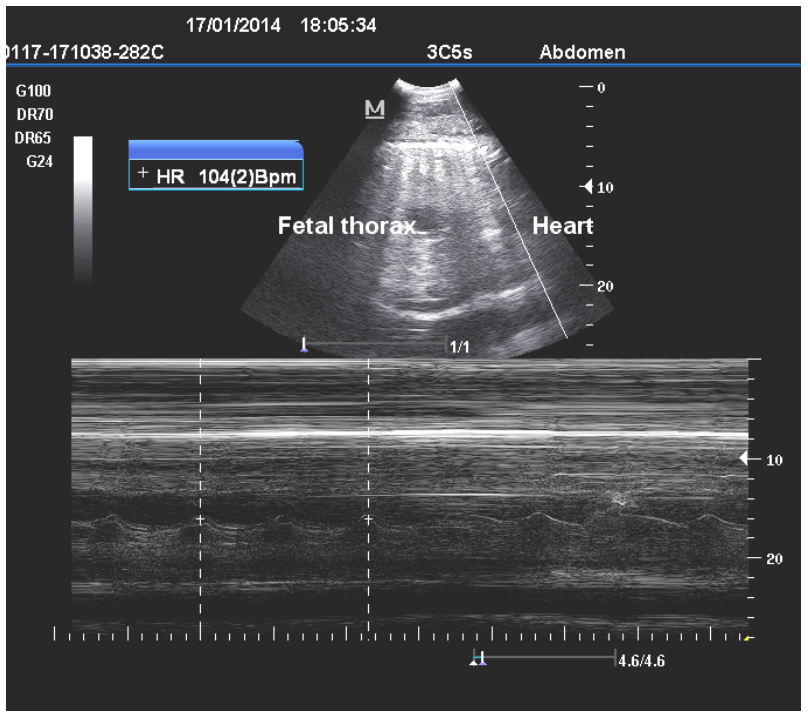

Fig. 4. Measurement of fetal heart rate (FHR) by M-mode ultrasonography (imaged with a 3.5-MHz macroconvex ultrasound probe in lateromedial direction in a 299 days pregnant warmblood mare)

A great variation in antepartum FHR pattern was found, while uterine contractions had no significant effect on FHR in the last month of gestation based on transabdominal Doppler ultrasound examinations (Jonker et al., 1994). Basal FHR (90 to $120 \mathrm{bpm}$ ) gradually decreased towards the end of parturition, with a marked loss in variability. Breukelman et al. (2006) used computer-assisted analysis after analogue-digital conversion of FHR data, which is more accurate than the data calculated by visual inspection of paper recordings (Jonker et al., 1994). The reference values for FHR were $108.6 \pm 1.9 \mathrm{bpm} 2$ days before expected calving, as compared to $109 \pm 1.9 \mathrm{bpm} 2$ weeks and $114.2 \pm 1.4 \mathrm{bpm} 3$ weeks before calving (Breukelman et al., 2006).

When decelerations (periodic decrease in FHR) occurred beyond the end of a contraction, the calf was born in poor condition (Jonker et al., 1994). In the acidotic group the mean baseline FHR increased from 113.5 to $138.6 \mathrm{bpm}$ during the last 55 minutes before birth, while in the normal group it changed from 116.9 to $121.3 \mathrm{bpm}$. Decelerations occurred during uterine contractions in acidotic fetuses and in the majority of normal fetuses (12 out of 16) during the expulsive stage of parturition; accelerations (periodic increase in FHR) were hardly recorded. The mean fall in FHR during a uterine contraction increased significantly towards birth. It is concluded that continuous intrapartum FHR measurements may provide additional information on the acidotic state of fetuses (Jonker et al., 1994); however, short-term measurements have no diagnostic value (Jonker et al., 1994). Therefore, at least 30-min continuous recordings are recommended in the cow (Breukelman et al., 2006). 
Transit-time ultrasonography during stage 2 of labour in cattle allows the direct and continuous measurement of umbilical blood flow volume per unit of time. It also allows us to investigate the relationships between umbilical blood flow, uterine contractions and fetal heart rate (Bleul et al., 2007). A decrease in blood flow is most likely caused by compression of the umbilical vessels during uterine contractions. Venous blood flow is more severely affected than arterial blood flow during strong contractions because the walls of the umbilical veins are thinner and have fewer muscle fibres than those of the umbilical arteries. Umbilical arterial and venous blood flow in acidotic calves was lower than that in non-acidotic calves during the last 30 minutes before birth (Bleul et al., 2007).

It has been reported that fetal breathing movements are present in lateterm human and equine fetuses and their absence can be a sign of acute fetal hypoxia (Manning et al., 1984; Reef et al., 1995, 1996; Palmer, 2000; Bucca et al., 2005). Fetal breathing movements are best visualised by watching the movement of the fetal diaphragm in relation to the fetal ribs. This can be difficult because of fetal and maternal activity (Palmer, 2000; Baska-Vincze et al., 2013).

Sometimes other fetal organs can be imaged (fetal gonads, stomach, intestines, liver, kidneys, lungs) and measured in both species; however, this is not as important in veterinary medicine as in human perinatology (Reef, 1998).

Fetal activity and tone are also critical components of the examinations. Fetal activity can be graded from 0 to 3 as described by Reef et al. (1995), and grade 2 or grade 3 is considered normal. The equine fetus is relatively active during the examinations; however, in the cow inactivity lasting 10 or more minutes can occur without any negative consequences (Buczinski, 2009). Fetal tone is present when the fetus flexes and extends the limbs, torso or neck, and fetal tone is absent if the fetus appears flaccid (Reef, 1998).

Fetal fluid quality and quantity are important parts of fetal monitoring during transabdominal ultrasonographic assessment. Allantoic fluid (in the majority of cases) and amniotic fluid are anechoic until late gestation and, in the horse near term, increased echogenicity can occur with small particles floating in the allantoic fluid (Reef et al., 1995, 1996; Bucca et al., 2005). However, in late-term cows, amniotic fluid is considered more echoic and allantoic fluid appears as a clear fluid (Buczinski, 2009). In the first and second trimester of equine and bovine pregnancy, increased echogenicity of the fetal fluids is considered to be pathological. The two kinds of fetal fluids are separated by a thin membrane called the amniotic membrane, which is often visualised near the forelimbs in both species (Reef et al., 1995, 1996; Buczinski, 2009). The quantity of fetal fluids can also be measured by ultrasonography, and too small or to large amounts of fluids are abnormal in both species. When monitoring fetal well-being, maximal fluid depths can be determined by multiple measurements on the lateral ventral abdomen of the dam (Reef, 1998, Baska-Vincze et al., 2014). 


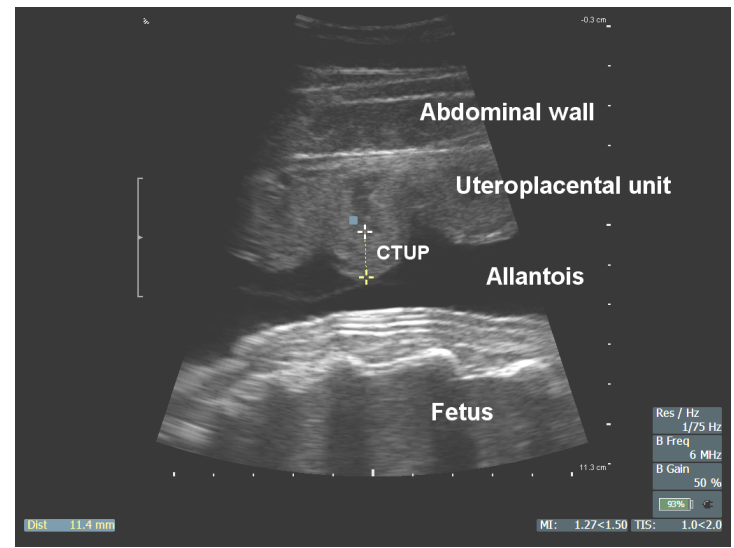

Fig. 5. Measurement of the combined thickness of the uteroplacental unit (CTUP; between the two callipers) by B-mode ultrasonography (imaged with a $3.5-\mathrm{MHz}$ macroconvex ultrasound probe in lateromedial direction in a 285 days pregnant warmblood mare)

An additional scanning measurement also critical for fetal well-being is the combined thickness of the uteroplacental unit (CTUP). The CTUP consists of two layers, an inner (sonolucent) and an outer (echogenic) one, but in most cases the placenta and the uterus cannot be distinguished as separate structures (Fig. 5). Thickness and continuity of this unit can be measured in the four quadrants of the mare's abdomen, and the unit is thickened in the case of placentitis, haemorrhage or oedema. Renaudin et al. (1997) reported normal CTUP values for pregnant mares $(\mathrm{n}=9)$. They measured CTUP in Quarter Horse, Thoroughbred and American Paint Horse breeds and the mean values for days 270-330 of gestation were between 8 and $12 \mathrm{~mm}$. According to the authors' ongoing study on equine well-being, in the breeding seasons of 2013 and 2014, 10 Lipizzaner mares were examined by transabdominal ultrasonography and CTUP measurements were made between days 280 and 315 of gestation. In these animals with normal pregnancies, CTUP was $12.7 \pm 3.1 \mathrm{~mm}$ (mean $\pm \mathrm{SD}$ ), which is higher than that reported by Renaudin et al. (1997). Therefore, there may be a difference in normal CTUP values between horse breeds but this parameter needs further investigation (Baska-Vincze et al., unpublished). Additionally, in these Lipizzaner broodmares fetal aortic diameter in the last month of gestation was $20.7 \pm 0.7 \mathrm{~mm}$ (mean \pm SD). Uteroplacental continuity must be checked on the whole uterus, because premature separation of the placenta is a life-threatening condition for the fetus. Discontinuity appears in horses as an anechoic area. Additionally, placental calcification has been observed in some cases and has been associated with abortion or a periparturient asphyxia syndrome (PAS) in the foal. Haemorrhages are rare in horses, but after a uterine torsion or a septic condition they can be observed (Reef, 1998). The cervical region of the uteroplacental unit can be properly 
scanned by rectal ultrasonographic examination (Bucca et al., 2005). In the cow, the anatomical structures are different, and in these animals the placentomes are easily visualised during scanning and their size can be measured (Fig. 6). In cloned pregnancies, much larger placentomes are often seen (Buczinski et al., 2009, 2011).

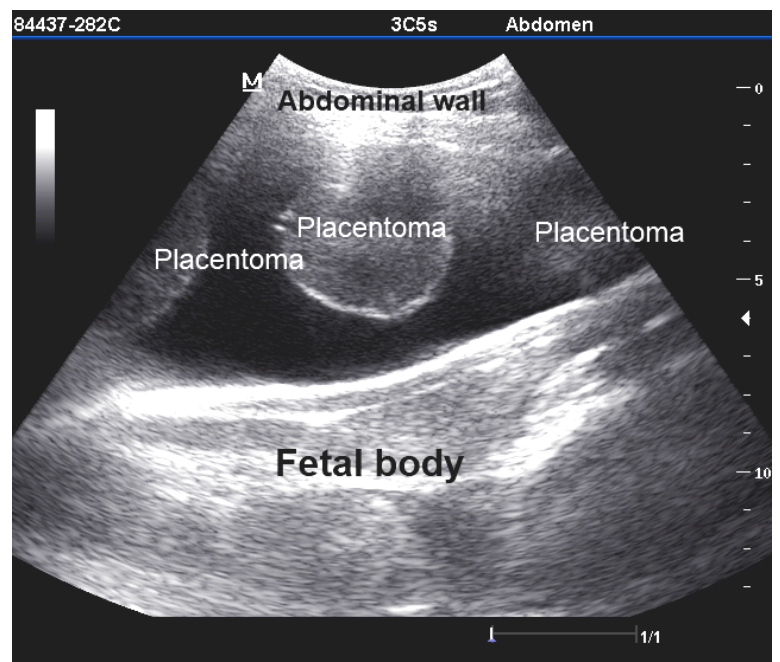

Fig. 6. Ultrasound image of three placentomes and the fetus in the cow (imaged with a $3.5-\mathrm{MHz}$ macroconvex ultrasound probe in right lateromedial direction in a 273 days pregnant HolsteinFriesian heifer)

\section{Ultrasonographic assessment in high-risk pregnancy}

In cattle, perhaps because of their utilisation different from that of horses, only few data are available about the management of at-risk or high-risk pregnant cows. In the horse, high-risk pregnancies have been studied in more detail and the need for advanced knowledge has been recognised. Although improved diagnostic techniques are available in equine reproduction, the incidence of pregnancy loss is still high, varying between 10 and $15 \%$ during gestation (Troedsson, 2007). During pregnancy, especially near term, specific conditions can affect pregnant mares. For instance, colic in late gestation can be a life-threatening condition; however, a retrospective study showed that only $18 \%$ of surviving mares having undergone colic surgery experienced pregnancy loss. In these cases, hypoxia and endotoxaemia could be identified as risk factors. Uterine torsion, prepubic tendon rupture, hydrops amnii or placentitis are also known to pose a significant threat to maternal, fetal and neonatal viability. All these conditions can be visualised and imaged by transabdominal and transrectal ultrasonography; thus, the use of this non-invasive technology for the examination of mares with normal or high-risk pregnancies has been recommended (Troedsson, 2007). 


\section{Future perspectives}

According to numerous publications, transabdominal fetal ultrasonography is an effective, useful and often essential method for examining the fetus and the dam in both mares and cows. There have been attempts to create a biophysical profile for both species, but these methods should be refined in order to obtain a higher specificity and sensitivity in animals, comparable to that achieved in human medicine. In the future, simple and low-cost methods should be developed for the evaluation of the pregnant dam and its fetus, in order to develop highly effective methods for the assessment of viability. More and more advanced techniques are available for clinicians and researchers, and attempts should be made to adapt these to everyday veterinary work also in the field.

\section{References}

Adams-Brendemuehl, C. and Pipers, F. S. (1987): Antepartum evaluations of the equine fetus. J. Reprod. Fertil. Suppl. 35, 565-573.

Baska-Vincze, B., Baska, F. and Szenci, O. (2014): Evaluation of fetal well-being by transabdominal ultrasonography in the mare. Preliminary results [in Hungarian, with English abstract]. Magyar Állatorvosok Lapja 136, 195-204.

Baska-Vincze, B., Rózsás, J. and Szenci, O. (2013): Assessment of fetal well-being by transabdominal ultrasonography in Hungarian broodmares under clinical and farm conditions. Proceedings of 13th WEVA Congress, Budapest, URL: http://www.ivis.org/proceedings/ weva/2013/oral/24.pdf?LA=1.

Bleul, U., Lejeune, B., Schwantag, S. and Kähn, W. (2007): Ultrasonic transit-time measurement of blood flow in the umbilical arteries and veins in the bovine fetus during stage II of labor. Theriogenology 67, 1123-1133.

Breukelman, S., Mulder, E. J. H., van Oord, R., Jonker, H., van der Weijden, B. C. and Taverne, M. A. M. (2006): Continuous fetal heart rate monitoring during late gestation in cattle by means of Doppler ultrasonography: reference values obtained by computer-assisted analysis. Theriogenology 65, 486-498.

Bucca, S., Fogarty, U., Collins, A. and Small, V. (2005): Assessment of feto-placental well-being in the mare from mid-gestation to term: Transrectal and transabdominal ultrasonographic features. Theriogenology 64, 542-557.

Buczinski, S. (2009): Ultrasonographic assessment of late term pregnancy in cattle. Vet. Clin. North Am. Food Anim. Pract. 25, 753-765.

Buczinski, S., Fecteau, G., Comeau, G., Boysen, S. R., Lefebvre, R. C. and Smith, L. C. (2009): Ultrasonographic fetal well-being assessment, neonatal and postpartum findings of cloned pregnancies in cattle: a preliminary study on 10 fetuses and calves. Can. Vet. J. 50, 261-269.

Buczinski, S. M. C., Fecteau, G., Lefebvre, R. C. and Smith, L. C. (2007): Fetal well-being assessment in bovine near-term gestations: current knowledge and future perspectives arising from comparative medicine. Can. Vet. J. 48, 178-183.

Buczinski, S., Fecteau, G., Lefebvre, R. C. and Smith, L. C. (2011): Assessment of fetal well-being in cattle by ultrasonography in normal, high-risk, and cloned pregnancies. Can. Vet. J. 52, 136-141.

Curran, S. and Ginther, O. J. (1995): M-mode ultrasonic assessment of equine fetal heart rate. Theriogenology 44, 609-617.

Held, T. H., Scheidegger, A. and Grunert, E. (1986): Cardiotocographic findings in healthy and asphyxiated cattle fetuses in the $2 \mathrm{~d}$ stage of labor. Zentralbl. Veterinärmed. A 33, 431-442. 
Jonker, F. H., van Oord, H. A., van Geijn, H. P., van der Weijden, G. C. and Taverne, M. A. (1994): Feasibility of continuous recording of fetal heart rate in the near term bovine fetus by means of transabdominal Doppler. Vet. Q. 16, 165-168.

Kotoyori, Y., Yokoo, N., Ito, K., Murase, H., Sato, F., Korosue, K. and Nambo, Y. (2012): Threedimensional ultrasound imaging of the equine fetus. Theriogenology 77, 1480-1486.

LeBlanc, M. M. (1996): Equine perinatology: What we know and what we need to know. Anim. Reprod. Sci. 42, 189-196.

Manning, F. A. (1990): The use of sonography in the evaluation of the high-risk pregnancy. Radiol. Clin. North Am. 28, 205-216.

Manning, F. A., Harman, C. R., Lange, I. R. and Morrison, I. (1986): Fetal assessment by biophysical profile scoring: 1985 update. Eur. J. Obstet. Gynecol. Reprod. Biol. 21, 331-339.

Manning, F. A., Lange, I. R., Morrison, I. and Harman, C. R. (1984): Fetal biophysical profile score and the nonstress test: a comparative trial. Obstet. Gynecol. 64, 326-331.

Manning, F. A., Menticoglou, S., Harman, C. R., Morrison, I. and Lange, I. R. (1987): Antepartum fetal risk assessment: the role of the fetal biophysical profile score. Baillieres Clin. Obstet. Gynaecol. 1, 55-72.

Manning, F. A., Morrison, I., Lange, I. R., Harman, C. R. and Chamberlain, P. F. (1985): Fetal assessment based on fetal biophysical profile scoring: experience in 12,620 referred high-risk pregnancies. I. Perinatal mortality by frequency and etiology. Am. J. Obstet. Gynecol. 151, 343-350.

Manning, F. A., Platt, L. D. and Sipos, L. (1980): Antepartum fetal evaluation: development of a fetal biophysical profile. Am. J. Obstet. Gynecol. 136, 787-795.

Ousey, J. C. and Fowden, A. L. (2012): Peter Rossdale's scientific contribution to equine perinatology. Equine Vet. J. 44, Issue Suppl. s41, 1-2.

Palmer, J. (2000): Fetal monitoring. Proceedings of the Equine Symposium and Annual Conference, San Antonio. pp. 39-43.

Pantaleon, L. G., Bain F. T., Zent, W. and Powell, D. G. (2003): Equine fetal growth and development. Vetlearn Compendium 25, 470-477.

Pipers, F. S. and Adams-Brendemuehl, C. S. (1984): Techniques and applications of transabdominal ultrasonography in the pregnant mare. J. Am. Vet. Med. Assoc. 185, 766-771.

Reef, V. B. (1998): Equine diagnostic ultrasound. Saunders, Philadelphia. 560 pp.

Reef, V. B., Vaala, W. E., Worth, L. T., Sertich, P. L. and Spencer, P. A. (1996): Ultrasonographic assessment of fetal well-being during late gestation: development of an equine biophysical profile. Equine Vet. J. 28, 200-208.

Reef, V. B., Vaala, W. E., Worth, L. T., Spencer, P. A. and Hammett, B. (1995): Ultrasonographic evaluation of the fetus and intrauterine environment in healthy mares during late gestation. Vet. Radiol. Ultrasound 36, 533-541.

Reimer, J. M. (1997): Use of transcutaneous ultrasonography in complicated latter-middle to late gestation pregnancies in the mare: 122 cases. Proceedings of the Annual Convention of the AAEP 1997, Vol. 43, 259-261.

Renaudin, C. D., Troedsson, M. H., Gillis, C. L., King, V. L. and Bodena, A. (1997): Ultrasonographic evaluation of the equine placenta by transrectal and transabdominal approach in the normal pregnant mare. Theriogenology 47, 559-573.

Szelényi, Z., Bajcsy, Á. Cs., Nagy, K., Répási, A., Brydl, E., Kulcsár, M., Huszenicza, Gy., Melo de Sousa, N., Beckers, J. F. and Szenci, O. (2011): Prediction of twin pregnancies by measuring certain endocrine parameters in dairy cows in the peripartal period. Oral presentation. In: Book of Proceedings, 12th Middle European Buiatrics Congress, Pula, Croatia, 2011. May 18-22. Veterinarska Stanica 42, Suppl. 1, 10-11.

Vaala, W. H. and Sertich, P. L. (1994): Management strategies for mares at risk for periparturient complications. Vet. Clin. North Am. Eq. Pract. 10, 237-265.

Troedsson, M. H. T. (2007): High risk pregnant mare. Acta Vet. Scand. 49, Suppl. 1, S9.

Whitcomb, M. E. (2008): Transabdominal fetal evaluation in the pregnant mare. Proceedings AMEVEQ Ultrasound Seminar, Bogota, Colombia, 19-21 June 2008. 